\title{
Enrichment of silk using eco-friendly natural dye extracted from Lichen (Flavoparmelia caperata)
}

Harsha Rawat, Ekta Sharma and Nargis Fatima

Received: 14.12.2017; Revised: 28.03.2018; Accepted: 15.04.2018

See end of the paper for authors' affiliations Harsha Rawat

Department of Clothing and Textiles, Home Science College, G.B. Pant University of Agriculture and Technology, Pantnagar, U.S. Nagar (Uttarakhand) India

Email : harsharawat.rawat@ gmail.com
ABSTRACT : Natural dyes are known for its soft and lustrous neutral colour. Now a day, it also gaining importance due to its eco-friendly nature with human being and environment. India has a rich sources of natural dyes and one of them are lichens. The lichens were traditionally used for dyeing the woollen yarn and fabric but after the invention of synthetic dyes, the use of lichen declines. In the present study among the different sources of Lichen, Flavoparmelia caperata was used to dye the silk fabric by standardise the dyeing recipe. Aqueous medium was used for the extraction of the dye. The dye was used for dyeing of degummed silk cloth and treated with four chemical auxiliaries i.e. Citric acid, Sodium sulphate, Oxalic acid and Tartaric acid. Study about fastness tests of dyed clothes was undertaken. Large range of shades was obtained because of varying chemical auxiliaries per cent and combination. It was observed that treatment with chemical auxiliaries improved the colourfastness properties of the dyed samples.

KEY WORDS: Natural dyes, Lichen, Flavoparmelia caperata, Chemical auxiliaries, Colourfastness properties

- HOW TO CITE THIS PAPER : Rawat, Harsha, Sharma, Ekta and Fatima, Nargis (2018). Enrichment of silk using eco-friendly natural dye extracted from Lichen (Flavoparmelia caperata). Asian J. Home Sci., 13 (1) : 134-138, DOI: 10.15740/HAS/AJHS/13.1/134-138. Copyright@ 2018: Hind Agri-Horticultural Society. 